\title{
Attenuation of extubation responses: Comparison of prior treatment with verapamil and dexmedetomidine
}

\author{
Tuhin Mistry, Shobha Purohit, Gunjan Arora, Nitesh Gill, Jaya Sharma
}

\begin{abstract}
Background: Tracheal extubation is almost always associated with stress response, airway response, and arrhythmias. There are many ways to attenuate this stress response. We have compared verapamil and dexmedetomidine on attenuation of these responses. Materials and Methods: Thirty patients (American Society of Anaesthesiologists Grade I, II) scheduled for spinal surgeries under general anaesthesia were randomly divided into two groups.At the end of surgery, after return of spontaneous efforts (bispectral index $>80$ ), in "GroupV" verapamil $0.1 \mathrm{mg} / \mathrm{kg}$ and in "Group D" dexmedetomidine $0.3 \mathrm{mcg} / \mathrm{kg}$ were administered as bolus intravenously over one minute. Heart rate (HR), systolic blood pressure (SBP), diastolic blood pressure (DBP), and mean arterial pressure (MAP) were recorded just before $\left(T_{0}\right)$ and 2 min after intravenous administration of study medications $\left(T_{M}\right)$, just after oral suction $\left(T_{S}\right)$, immediately after extubation $\left(T_{E}\right)$ and $I, 3,5$ and 10 min postextubation $\left(E_{1}, E_{3}, E_{5}, E_{10}\right)$. Duration of emergence and extubation, quality of extubation, Richmond Agitation Sedation Scale (RASS) score and time to reach modified Aldrete score $\geq 9$ were compared. Results: HR, SBP, DBP, MAP were higher in GroupV than Group D, but statistically insignificant $(P>0.05)$. Extubation quality scores was I for $20 \%, 2$ for $60 \%$ and 3 for $20 \%$ patients in GroupV, whereas I in $80 \%, 2$ in $20 \%$ in Group D.There was occurrence of bradycardia within 2 min of administration of drug in one patient in Group D. RASS score was in the range of $-\mathrm{I}$ to $+\mathrm{I}$ in $>90 \%$ patient in Group V, whereas -3 to $-\mathrm{I}$ in $80 \%$ cases in Group D. Conclusion: Single dose of dexmedetomidine $(0.3 \mathrm{mcg} / \mathrm{kg})$ given before extubation produced significant attenuation of circulatory and airway responses during extubation as compared to verapamil $(0.1 \mathrm{mg} / \mathrm{kg})$.
\end{abstract}

Key words: Dexmedetomidine, extubation responses, verapamil

\section{INTRODUCTION}

Tracheal extubation is associated with acute, transient, significant and undesirable haemodynamic and airway responses that may persist into the recovery period. Stimulation of the respiratory tract at the supraglottic and subglottic levels and an increase in the release of circulatory catecholamines produce these responses. ${ }^{[1]}$ The reflexes ranges from tachycardia, hypertension,

\begin{tabular}{|l|l|}
\hline \multicolumn{2}{|c|}{ Access this article online } \\
\hline Quick Response Code: & Website: \\
\hline & www.jnaccjournal.org \\
\cline { 2 - 2 } & \\
\hline
\end{tabular}

coughing, bucking, agitation to bronchospasm, laryngospasm, laryngeal oedema, negative pressure pulmonary oedema, arrhythmias, left ventricular failure, myocardial ischaemia, increased bleeding, raised intracranial and intraocular pressure and cerebrovascular haemorrhage in susceptible individuals..$^{[2]}$ Although most patients can tolerate these transient effects without any significant consequences, but this could be detrimental in patients operated for cardiac, neuro or ophthalmic lesions. As per Difficult Airway Society basic extubation guideline, cardiovascular and airway factors need to be optimized before extubation.

Several techniques, as well as drugs, have been used to attenuate these responses during tracheal extubation. Techniques like extubation in a deeper plane of anaesthesia, ${ }^{[3]}$ substitution of the Endotracheal Tube with a laryngeal mask airway ${ }^{[4]}$ and drugs like low-dose propofol, ${ }^{[5]} \beta_{1}$ blockers like esmolol, ${ }^{[6]}$ landiolol; $^{[7]}$

Department of Anaesthesiology and Critical Care, Sawai Man Singh Medical College and Attached Group of Hospitals, Jaipur, Rajasthan, India

Address for correspondence:

Dr. Tuhin Mistry, Room No A-92, Resident Doctor's Hostel, Sawai Man Singh Medical College, JLN Marg, Jaipur - 302 004, Rajasthan, India.

E-mail: dr.tuhin2014@gmail.com 
combined $\alpha-\beta$ blocker like labetalol; ${ }^{[8]} \mathrm{Ca}^{2+}$ channel blockers like diltiazem, ${ }^{[9]}$ verapamil, ${ }^{[10]}$ nicardipine; ${ }^{[11]}$ intravenous lignocaine, ${ }^{[12]}$ lidocaine spray, ${ }^{[13]}$ intracuff lignocaine; ${ }^{[14]}$ low dose iv opioids like fentanyl, ${ }^{[15]}$ remifentanil, ${ }^{[16]}$ alfentanil, ${ }^{[17]}$ sufentanil; ${ }^{[18]}$ central sympatholytics like clonidine, ${ }^{[19]}$ dexmedetomidine; ${ }^{[20]}$ vasodilators like nitrates, ${ }^{[21]}$ prostaglandin ${ }^{[22]}$ and $\mathrm{MgSO}_{4}{ }^{[23]}$ have been studied as sole agent or in comparison with each other to control haemodynamic changes and upper airway tract events with variable success rates.

Rapid and smooth emergence after general anaesthesia in spinal surgery is desirable to allow early neurological examination. Till date, no study in literature has compared the effects of verapamil and dexmedetomidine for attenuation of extubation reflexes. In the present study, we have attempted to evaluate and compare the efficacy of intravenous verapamil (phenylalkylamine group of calcium channel blocker) and dexmedetomidine ( $\alpha_{2}$-adrenoceptor agonist) on attenuation of airway and haemodynamic responses following tracheal extubation in patients undergoing elective spinal surgery under general anaesthesia.

\section{MATERIALS AND METHODS}

This study was conducted in the department of Anaesthesioloy in Neurosurgery Operation Theatre at Tertiary Care Centre. This prospective, randomised, double-blind study included 30 patients of American Society of Anesthesiologists Grade I and II, age 2050 years, body weight $50-70 \mathrm{~kg}$ who underwent spinal surgeries in the elective theater. Prior ethical permission was taken from our Institutional Ethical Committee and Review Board and written informed consent was obtained from all patients enrolled for the study.

Patients with history of respiratory, cardiac, hepatic, renal or metabolic disorder, convulsion, allergy to the drug used, bleeding disorder, severe neurological deficit or low Glasgow Coma Scale (GCS) score, chronic alcohol or drug abuse, patients being treated with drugs like adrenoceptor agonist or antagonist, digoxin, anticonvulsants or psychotropic medications, pregnant or lactating mother, patients with bradycardia, hypertension, severe hypovolemia were excluded from the study. Other exclusion criteria included patients with suspicious difficult intubation or who required multiple attempts for intubation and those who required postoperative mechanical ventilation.

The patients were randomized on the day of surgery into two groups each of 15 patients by chit in box method. Medications were prepared and hidden behind drapes and administered by one anaesthesiologist, and observations were made by another anaesthesiologist who was blinded to the group to which the patient was assigned. In Group V, 15 patients received $0.1 \mathrm{mg} / \mathrm{kg}$ verapamil and in Group D, 15 patients received $0.3 \mathrm{mcg} / \mathrm{kg}$ dexmedetomidine. All the drugs were prepared in identical syringes diluted with isotonic normal saline to make a total volume of $10 \mathrm{ml}$.

Patients were kept nil per oral from midnight before surgery. After shifting the patient to the elective operation theater, two large bore (18 G) intravenous access were obtained, and Ringer lactate was started at the rate of $10 \mathrm{ml} / \mathrm{kg} / \mathrm{h}$. Preinduction monitors like pulse oximeter, noninvasive blood pressure, 5-lead electrocardiogram were connected and heart rate (HR), systolic blood pressure (SBP), diastolic blood pressure (DBP), mean arterial pressure (MAP), $\mathrm{SpO}_{2}$ were recorded at this time. Patients were premedicated with intravenous midazolam $(0.02 \mathrm{mg} / \mathrm{kg})$, glycopyrrolate $(0.005 \mathrm{mg} / \mathrm{kg})$ and fentanyl $(2 \mathrm{mcg} / \mathrm{kg})$. After preoxygenation for $3 \mathrm{~min}$, general anaesthesia was induced with inj. thiopental sodium $5 \mathrm{mg} / \mathrm{kg}$ followed by inj. rocuronium $1 \mathrm{mg} /$ $\mathrm{kg}$ was given to facilitate direct laryngoscopy and orotracheal intubation (high-volume/low-pressure cuffed endotracheal tubes). The internal diameter of the endotracheal tube was 7-7.5 $\mathrm{mm}$ for women and $8-8.5 \mathrm{~mm}$ for men. All the patients were mechanically ventilated at a fresh gas flow of $4 \mathrm{~L} / \mathrm{min}$ and anaesthesia was maintained with sevoflurane in nitrous oxide and oxygen (60:40) (minimum alveolar concentration $0.8-1.0)$ and vecuronium $(0.02 \mathrm{mg} / \mathrm{kg}$ every $30-40 \mathrm{~min})$ throughout the surgical procedure. Intraoperative analgesia was supplemented with incremental doses of fentanyl every hour. Intraoperatively $\mathrm{EtCO}_{2^{\prime}}$ bispectral index (BIS), temperature, and urine output were also monitored. During mechanical ventilation, a respiratory rate of $12-16 / \mathrm{min}$ and tidal volume of $8-10 \mathrm{ml} / \mathrm{kg}$ were used, which were adjusted to keep normocapnia and normoxia with oxygen saturation $\geq 98 \%$. Ringer lactate and normal saline were used for replacement and maintenance. Colloids, blood and blood products were used if required.

At the end of surgery, all anesthetic agents were discontinued, and patients were ventilated with $100 \%$ oxygen. After dressing of the surgical wound, the patient was turned supine. On the return of spontaneous efforts (BIS > 80), study drugs were administered over $60 \mathrm{~s}$. Neuromuscular blockade was reversed with neostigmine $0.05 \mathrm{mg} / \mathrm{kg}$ and glycopyrrolate $0.01 \mathrm{mg} / \mathrm{kg}$. Oropharyngeal secretions were gently aspirated by suction catheter. Once patient became conscious and responded to verbal commands extubation was performed. After extubation, the patients were oxygenated with $100 \%$ oxygen for $5 \mathrm{~min}$. The values for HR, SBP, DBP and MAP were obtained just before administration of the study drug (baseline value, $\mathrm{T}_{0}$ ), 
2 min after the injection of study medications $\left(\mathrm{T}_{\mathrm{M}}\right)$, just after oral suction $\left(\mathrm{T}_{\mathrm{S}}\right)$, immediately after extubation $\left(\mathrm{T}_{\mathrm{E}}\right)$ and $1,3,5$ and 10 min postextubation $\left(\mathrm{E}_{1}, \mathrm{E}_{3^{\prime}}, \mathrm{E}_{5^{\prime}}, \mathrm{E}_{10}\right)$ and compared among the two groups. Duration of emergence and extubation were also compared.

The quality of extubation was assessed with a five-point scale, ${ }^{[24]}$ where (1) no cough, smooth extubation, (2) smooth extubation, minimal coughing (1-2 times), (3) moderate coughing ( 3 or 4 times), (4) severe coughing ( 5 to 10 times) and difficulty in breathing, (5) poor extubation, very uncomfortable and forced breathing (laryngospasm and coughing $>10$ times). After extubation, all these patients were also observed for sedation by Richmond Agitation Sedation Score (RASS). ${ }^{[25]}$ Time to reach modified Aldrete Score $\geq 9$ from the termination of anaesthesia was noted for early shifting of patients from recovery unit to the neurosurgical ward for supportive care.

We defined following terms for the study:

- Hypotension $=\mathrm{SBP}<20 \%$ of baseline value or $90 \mathrm{mmHg}$ or MAP $<60 \mathrm{mmHg}$ whichever is lower

- Hypertension $=\mathrm{SBP}>20 \%$ of baseline value or $150 \mathrm{mmHg}$, whichever is higher

- Tachycardia $=\mathrm{HR}>25 \%$ of baseline value.

- Bradycardia $=\mathrm{HR}<60 \mathrm{bpm}$.

Emergence time $=$ the time interval between discontinuing of anesthetic agents and patient following verbal commands.

Extubation time $=$ the time interval between cessation of anesthetic agents and tracheal extubation.

Various complications such as desaturation, breath holding, laryngospasm, bronchospasm, bradycardia, hypotension, nausea, vomiting, restlessness, etc., were also noted.

\section{Statistical analysis}

The sample size was calculated 15 subjects in each group with alpha error 0.05 and power $80 \%$, based on a pilot study on 10 patients, with the quality of extubation (extubation score) as the primary outcome. Sample size was calculated by Primer of Biostatistics software version 6.0 (by Stanton A. Glantz, (c) 2005 McGraw-Hill) and analysis of the statistical data obtained from study was carried out by Statistical Package for the Social Sciences software version 21 (SPSS Inc., Chicago, Illinois, USA). The categorical measurements were summarized as the number and percentage, continuous measurements as the arithmetic mean and standard deviation. The numerical data were analyzed using Student's $t$-test. Corresponding ' $P$ ' values were also calculated. Statistical significance was accepted as not significant and significant at $P>0.05$ and $P<0.05$, respectively. Statistical significance of extubation scores was obtained using Mann-Whitney U-test.

\section{RESULTS}

A total of 30 patients were included in this randomized, double-blind trial, and none excluded from final analysis. No statistical differences were found with respect to age, sex, weight, preinduction and baseline HR, SBP, DBP, and MAP between the two groups [Tables 1 and 2].

In Group D, a statistically significant $(P<0.05)$ decrease in $\mathrm{HR}$ was observed up to $\mathrm{E}_{10}$ stage, whereas in Group V, at these stages changes were statistically insignificant $(P>0.05)$ [Figure 1]. In intergroup comparison, these changes were statistically insignificant $(P>0.05)$. Bradycardia occurred in one patient within 2 min of drug administration in Group D.

The MAP between the two groups showed the statistically significant difference $(P<0.05)$ at stage $\mathrm{T}_{\mathrm{M}}$ and $\mathrm{E}_{10}$. Immediately after suction $\left(\mathrm{T}_{\mathrm{S}}\right)$, MAP was low in Group D compared to $\mathrm{T}_{0}$ stage and Group V, but statistically insignificant $(P>0.05)$. Immediately after extubation $\left(\mathrm{T}_{\mathrm{E}}\right)$, there was an increase in MAP in both the groups but statistically insignificant $(P>0.05)$ [Figure 2].

None of the patient required any medical intervention for fluctuation in haemodynamic parameters.

Extubation quality score was noted at the time of extubation. $80 \%$ of the patients in Group D could be

Table 1: Demographic data (mean $\pm S D)$

\begin{tabular}{lccc}
\hline Parameters & $\begin{array}{c}\text { Group V } \\
(\boldsymbol{n}=\mathbf{1 5})\end{array}$ & $\begin{array}{c}\text { Group D } \\
(\boldsymbol{n}=\mathbf{1 5})\end{array}$ & $\boldsymbol{P}$ \\
\hline Age (years) & $40.4 \pm 13.2$ & $42.2 \pm 13.5$ & 0.715 \\
Sex (male/female) & $11 / 4$ & $11 / 4$ & 0.680 \\
ASA status (I:II) & $11: 4$ & $13: 2$ & 0.684 \\
Weight (kg) & $60.5 \pm 6.5$ & $60.4 \pm 13.8$ & 0.974 \\
\hline
\end{tabular}

$n=$ Number of patients, Group V = Verapamil, $\mathrm{D}=$ Dexmedetomidine, ASA = American Society of Anesthesiologists, $S D=$ Standard deviation

Table 2: Preoperative haemodynamic (mean \pm SD)

\begin{tabular}{lccc}
\hline Parameters & $\begin{array}{c}\text { Group V } \\
(\boldsymbol{n}=\mathbf{1 5})\end{array}$ & $\begin{array}{c}\text { Group D } \\
(\boldsymbol{n}=\mathbf{1 5})\end{array}$ & $\boldsymbol{P}$ \\
\hline HR (bpm) & $89.9 \pm 18.2$ & $92.4 \pm 17.3$ & 0.698 \\
SBP (mmHg) & $125.9 \pm 10.3$ & $127.3 \pm 9.5$ & 0.702 \\
DBP (mmHg) & $87.9 \pm 7.3$ & $83.3 \pm 4.9$ & 0.054 \\
MAP (mmHg) & $100.5 \pm 6.7$ & $97.9 \pm 5.36$ & 0.258 \\
\hline
\end{tabular}

$n=$ Number of patients, Group V = Verapamil, $\mathrm{D}=$ Dexmedetomidine, $\mathrm{SBP}=$ Systolic blood pressure, $\mathrm{DBP}=$ Diastolic blood pressure, $\mathrm{MAP}=$ Mean arterial pressure, $\mathrm{SD}=$ Standard deviation, $\mathrm{HR}=$ Heart rate 
extubated smoothly with no coughing (Grade1), whereas $60 \%$ patients in Group V showed minimal coughing at the time of extubation (Grade 2) [Figure 3].

RASS score was in the range of -1 to +1 in $>90 \%$ patient in Group V whereas -3 to -1 in $80 \%$ cases in Group D [Figure 4]. So, a higher degree of sedation was noted in Group D whereas in Group V most of the patients were anxious and agitated or restless.

There was no statistically significant difference between the duration of surgery and duration of anaesthesia between the two groups. Mean emergence and extubation times were slightly higher in Group D but not statistically significant $(P=0.228$ and $P=0.075)$. The median time to reach Modified Aldrete score $\geq 9$ was also statistically insignificant between the two groups [Table 3].

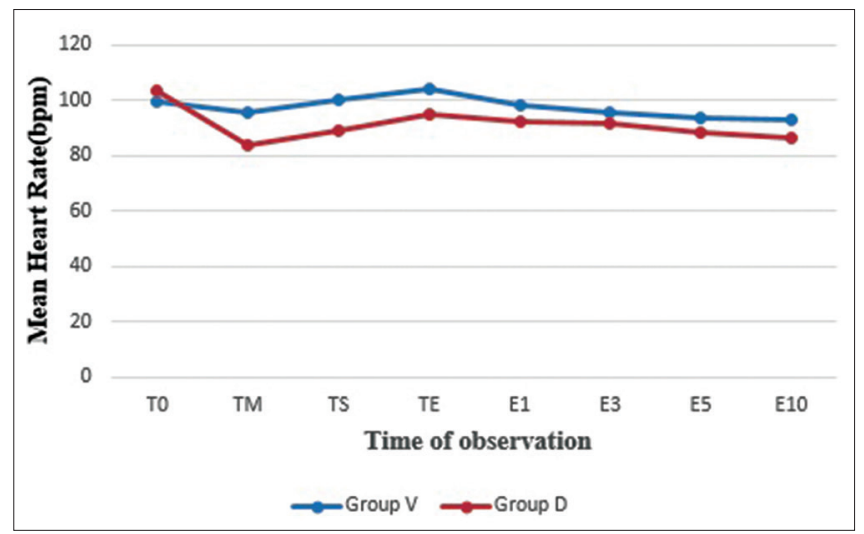

Figure 1: Changes in mean heart rate (bpm). Measurement points = $T_{0}$ : Just before administration of the study drug (Baseline values), $T_{M}$ : 2 min after injection of study medications, $T_{S}$ : Just after oral suction, $\mathrm{T}_{\mathrm{E}}$ : Immediately after extubation, $\mathrm{E}_{1}, \mathrm{E}_{3}, \mathrm{E}_{5}, \mathrm{E}_{10}: 1,3,5$ and $10 \mathrm{~min}$ postextubation; $\mathrm{V}=$ Verapamil, $\mathrm{D}=$ Dexmedetomidine

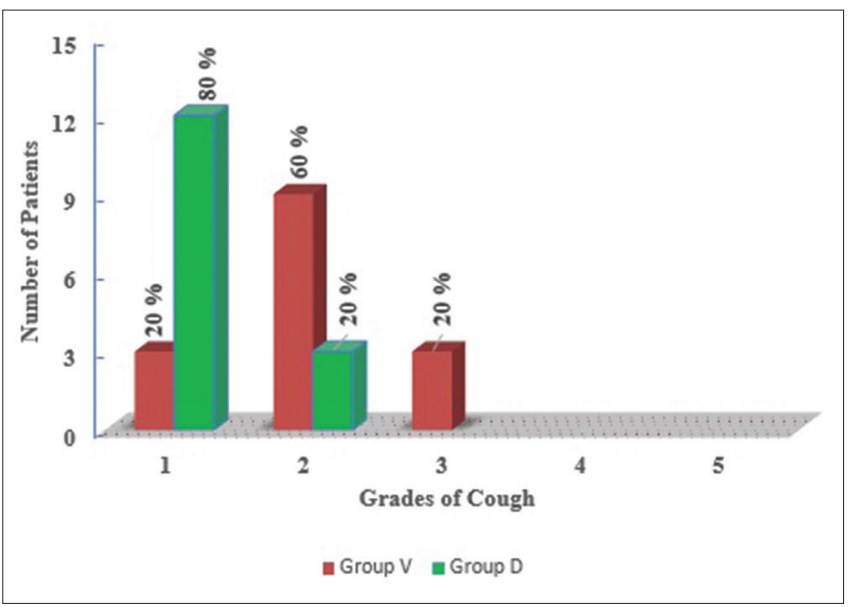

Figure 3: Comparison of extubation score. Grades of cough: $1=$ Grade 1, $2=$ Grade 2, $3=$ Grade 3, $4=$ Grade 4 and $5=$ Grade 5; $\mathrm{V}=$ Verapamil, $\mathrm{D}=$ Dexmedetomidine,$P=0.00298$

\section{DISCUSSION}

Anaesthesiologists are most worried about problems associated with extubation, recovery and emergence as these are more common than problems at intubation and many aspects are controversial with no clear guidelines or protocols. Tracheal extubation is associated with a $10-30 \%$ increase in arterial pressure and HR lasting 5-15 min. Respiratory complications after tracheal extubation are 3 times more common than complications occurring during tracheal intubation and induction of anaesthesia ( $4.6 \% \mathrm{vs}$. $12.6 \%) .{ }^{[26]}$ Hence, we decided to do a comparative study on alleviation of this response with pharmacological agents.

The main findings of our study are as follows:

- The HR was maintained below the baseline value in Group D but increased in Group V immediately after suction and extubation. Only one patient had bradycardia in Group D

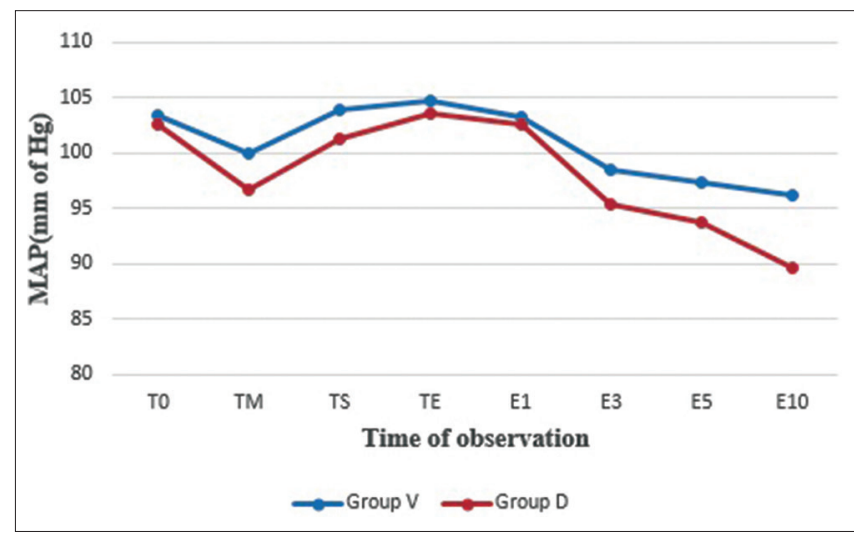

Figure 2: Changes in mean arterial pressure (mean \pm standard deviation). Measurement points $=\mathrm{T}_{0}$ : Just before administration of the study drug (Baseline values), $\mathrm{T}_{\mathrm{M}}$ : $2 \mathrm{~min}$ after injection of study medications, $T_{S}$ : Just after oral suction, $T_{E}$ : Immediately after extubation, $E_{1}, E_{3}, E_{5}, E_{10}: 1,3,5$ and 10 min postextubation; $\mathrm{V}=$ Verapamil, $\mathrm{D}=$ Dexmedetomidine

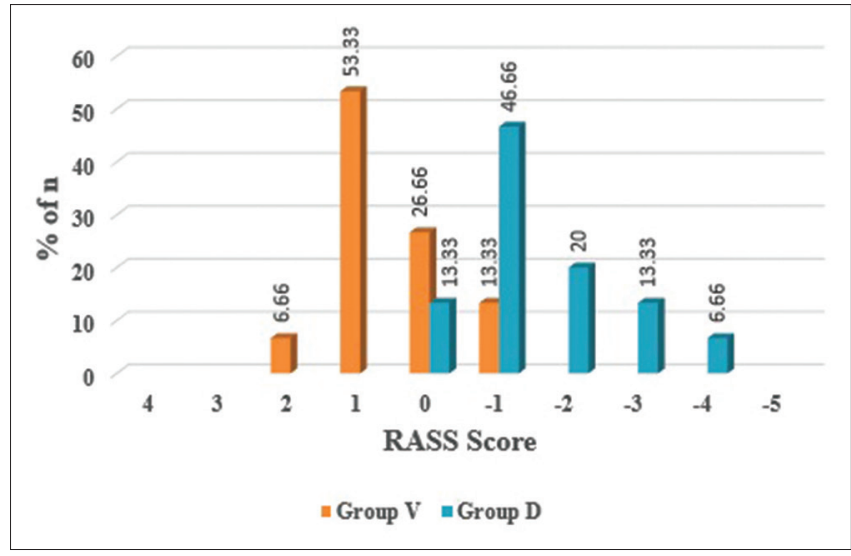

Figure 4: Richmond Agitation Sedation Scale score after extubation in two groups. $n=$ number of patients, Group $V=$ Verapamil, Group $\mathrm{D}=$ Dexmedetomidine 
Table 3: Other parameters

\begin{tabular}{lccc}
\hline Parameters (min) & $\begin{array}{c}\text { Group V } \\
(\boldsymbol{n}=\mathbf{1 5})\end{array}$ & $\begin{array}{c}\text { Group D } \\
(\boldsymbol{n}=\mathbf{1 5})\end{array}$ & $\boldsymbol{P}$ \\
\hline $\begin{array}{l}\text { Duration of surgery } \\
\text { (mean } \pm \text { SD) }\end{array}$ & $141.3 \pm 29.5$ & $144.7 \pm 24.4$ & 0.739 \\
$\begin{array}{l}\text { Duration of anaesthesia } \\
\text { (mean } \pm \text { SD) }\end{array}$ & $164.7 \pm 31.6$ & $168.7 \pm 25.6$ & 0.706 \\
$\begin{array}{l}\text { Emergence time (mean } \pm S D) \\
\text { Extubation time (mean } \pm S D)\end{array}$ & $7.06 \pm 0.70$ & $7.33 \pm 0.48$ & 0.228 \\
$\begin{array}{l}\text { Median time to reach } \\
\text { modified Aldrete score } \geq 9\end{array}$ & 11 & $8.73 \pm 0.59$ & 0.075 \\
\hline $\begin{array}{l}n=\text { Number of patients, Group V = Verapamil, D = Dexmedetomidine, } \\
\text { SD = Standard deviation }\end{array}$ & & & $>0.05$ \\
\end{tabular}

- The SBP, DBP, MAP were increased above the baseline, but dexmedetomidine attenuated the increase in blood pressure (BP) better than verapamil

- The airway response was better attenuated with dexmedetomidine than with verapamil

- A higher degree of sedation was noted in dexmedetomidine group

- No difference in median time to achieve required Aldrete score in between two groups.

Different studies in the literature have recommended the use of verapamil to control circulatory responses occurring during extubation. However, intravenous verapamil has short onset of action of about $30 \mathrm{~s}$, peak action in 2-3 min, brief duration of action due to rapid redistribution, that is, up to $10 \mathrm{~min}$, excellent negative chronotropic and negative inotropic effect. Jajoo et al. studied two different doses of verapamil and suggested that a bolus injection of verapamil $0.1 \mathrm{mg} / \mathrm{kg}$ given 2 min before tracheal extubation is a more effective prophylactic for attenuating the cardiovascular changes associated with extubation than $0.05 \mathrm{mg} / \mathrm{kg}$ dose. ${ }^{[10]}$ Mikawa et al. compared the effect of intravenous injection of verapamil and diltiazem and concluded that a bolus injection of verapamil $0.1 \mathrm{mg} / \mathrm{kg}$ is a more effective than is diltiazem $0.2 \mathrm{mg} / \mathrm{kg}$ in attenuation of cardiovascular response. ${ }^{[27]}$ Mikawa et al. in another study concluded that a combination of verapamil $0.1 \mathrm{mg} / \mathrm{kg}$ and lidocaine $1 \mathrm{mg} / \mathrm{kg}$ is superior to each drug alone for suppressing the hypertensive and tachycardic responses to tracheal extubation. ${ }^{[28]}$ Hence, we used verapamil $0.1 \mathrm{mg} / \mathrm{kg}$ in our study.

Dexmedetomidine is a highly selective $\alpha_{2}$ agonist, which has potent sedative, anxiolytic and analgesic activity. It activates receptors in the medullary vasomotor center, reducing norepinephrine turnover and decreasing central sympathetic outflow, resulting in alterations in sympathetic function and decreased HR and BP. In our study, there was lesser rise in HR and MAP during suction $\left(\mathrm{T}_{\mathrm{S}}\right)$ and extubation $\left(\mathrm{T}_{\mathrm{E}}\right)$ in Group D compared to Group V which could be due to dexmedetomidine induced sedation, analgesia and decreased catecholamine levels, inhibition of central sympathetic outflow and enhanced vagal activity.

The degree of haemodynamic effects depends on the dose and fluid status of the patient. In the peripheral blood vessels, direct action on $\alpha_{2 \mathrm{~B}}$ receptors produces vasoconstriction, which may lead to hypertension. Sharma et al. studied the effect of bolus administration of dexmedetomidine $0.5 \mathrm{mcg} / \mathrm{kg}$ over $60 \mathrm{~s}$ in patients undergoing spinal surgeries and observed increase in MAPs in the first 2 min after drug administration, which returned to normal values after 3 min. ${ }^{[29]}$ We did not experience such transient hypertension in our study with the dose of $0.3 \mathrm{mcg} / \mathrm{kg}$.

The activation of $\alpha_{2}$ adrenoceptors especially in the nucleus tractus solitarius by dexmedetomidine causes bradycardia. Bindu et al. studied the effect of intravenous dexmedetomidine infusion $0.75 \mathrm{mcg} / \mathrm{kg}$ given $15 \mathrm{~min}$ prior to extubation and concluded that dexmedetomidine stabilises haemodynamic and facilitates smooth extubation, but there was bradycardia in 13 patients out of 25 patients. ${ }^{[30]}$ Aksu et al. compare the effects of dexmedetomidine $(0.5 \mathrm{mcg} / \mathrm{kg})$ and fentanyl $(1 \mathrm{mcg} / \mathrm{kg})$ in patients undergoing rhinoplasty and concluded that dexmedetomidine was more effective in attenuating airway reflex responses to tracheal extubation and maintaining haemodynamic stability compared to fentanyl but was associated with bradycardia in two patients out of 20 patients. ${ }^{[1]}$ Guler et al. studied the effect of a single bolus dose of dexmedetomidine $(0.5 \mu \mathrm{g} / \mathrm{kg})$ intravenously over $60 \mathrm{~s}$ in patients undergoing intraocular surgery and experienced bradycardia in one patient and hypotension in three patients out of 30 patients. ${ }^{[2]} \mathrm{Ali}$ and Abdellatif compared the effect of a single dose of dexmedetomidine $(0.3 \mu \mathrm{g} / \mathrm{kg})$ and propofol $(1 \mathrm{mg} / \mathrm{kg})$ administered prior to termination of sevoflurane-based anaesthesia on the incidence and severity of emergence agitation in children and found that dexmedetomidine was more effective than propofol without any incidence of bradycardia. ${ }^{[32]}$ We used dexmedetomidine in a low dose $(0.3 \mu \mathrm{g} / \mathrm{kg})$ and observed bradycardia in one patient, but no incidence of hypotension.

In vitro studies indicate that $\alpha_{2}$ receptor stimulation can cause smooth muscle relaxation thereby preventing bronchoconstriction. ${ }^{[29]}$ In our study, there was decrease incidence of cough in dexmedetomidine group during extubation.

The sedative and anxiolytic effects of dexmedetomidine result primarily from its activity in the locus coeruleus of the brain stem. Riessen et al. investigated the newly introduced RASS for better monitoring of sedation depth and concluded that, in routine use Ramsay score 
showed a poor performance than RASS regarding the measurement of sedation depth. ${ }^{[25]}$ Hence, we used RASS score in our study and found that most patients in Group D were drowsy, that is, not fully alert but has sustained awakening to voice (RAAS-1) after extubation whereas in Group V, most patients belonged to RAAS + 1 .

In our study, none of the patients in either group developed respiratory depression, laryngospasm or bronchospasm.

In our study, we did not measure the plasma norepinephrine levels, which could precisely predict the suppression of the sympathetic response to extubation.

\section{CONCLUSION}

We concluded that, dexmedetomidine is more effective in attenuation of extubation responses in terms of better extubation score and better haemodynamic control compared with verapamil except that it can cause bradycardia and more sedation in neurosurgical patients. However caution to be observed in patients with preexisting bradycardia or low GCS.

\section{REFERENCES}

1. Elokda SA, ElShamaa HA. Effect of esmolol infusion on myocardial oxygen consumption during extubation and quality of recovery in elderly patients undergoing general anesthesia: Randomized, double blinded, clinical trial. Egypt J Anaesth 2015;31:135-42.

2. Kothari D, Tandon N, Singh M, Kumar A. Attenuation of circulatory and airway responses to endotracheal extubation in craniotomies for intracerebral space occupying lesions: Dexmedetomidine versus lignocaine. Anesth Essays Res 2014;8:78-82.

3. Conti J, Smith D. Haemodynamic responses to extubation after cardiac surgery with and without continued sedation. $\mathrm{Br}$ J Anaesth 1998;80:834-6.

4. Koga K, Asai T, Vaughan RS, Latto IP. Respiratory complications associated with tracheal extubation. Timing of tracheal extubation and use of the laryngeal mask during emergence from anaesthesia. Anaesthesia 1998;53:540-4.

5. Moein Vaziri MT, Jouybar R, Moein Vaziri N, Moein Vaziri N, Panah A. Attenuation of cardiovascular responses and upper airway events to tracheal extubation by low dose propofol. Iran Red Crescent Med J 2013;15:298-301.

6. Alkaya MA, Saraçoğlu KT, Pehlivan G, Eti Z, Göğuiş FY. Effcts of esmolol on the prevention of haemodynamic responses to tracheal extubation after craniotomy operations. Turk J Anaesth Reanim 2014;42:86-90.

7. Shirasaka T, Iwasaki T, Hosokawa N, Komatsu M, Kasaba T, Takasaki M. Effects of landiolol on the cardiovascular response during tracheal extubation. J Anesth 2008;22:322-5.

8. Kross RA, Ferri E, Leung D, Pratila M, Broad C, Veronesi $\mathrm{M}$, et al. A comparative study between a calcium channel blocker (Nicardipine) and a combined alpha-beta-blocker (Labetalol) for the control of emergence hypertension during craniotomy for tumor surgery. Anesth Analg 2000;91:904-9.

9. Nishina K, Mikawa K, Maekawa N, Obara H. Attenuation of cardiovascular responses to tracheal extubation with diltiazem. Anesth Analg 1995;80:1217-22.

10. Jajoo SS, Chaudhari AR, Singam A, Chandak A. Attenuation of hemodynamic responses to endotracheal extubation: A prospective randomised controlled study between two different doses of verapamil. Int J Biomed Res 2013;4:663-9.

11. Kovac AL, McKinley C, Tebbe CJ, Williams C. Comparison of nicardipine versus placebo to control hemodynamic responses during emergence and extubation. J Cardiothorac Vasc Anesth 2001;15:704-9.

12. Savitha KS, D'Souza JS, Kothari AN. Attenuation of hemodynamic response to extubation with i.v. lignocaine: A randomized clinical trial. J Evol Med Dent Sci 2014;3:838-46.

13. Lee DH, Park SJ. Effects of $10 \%$ lidocaine spray on arterial pressure increase due to suspension laryngoscopy and cough during extubation. Korean J Anesthesiol 2011;60:422-7.

14. Fagan C, Frizelle HP, Laffey J, Hannon V, Carey M. The effects of intracuff lidocaine on endotracheal-tube-induced emergence phenomena after general anesthesia. Anesth Analg 2000;91:201-5.

15. Nishina K, Mikawa K, Maekawa N, Obara H. Fentanyl attenuates cardiovascular responses to tracheal extubation. Acta Anaesthesiol Scand 1995;39:85-9.

16. Mahoori A, Noroozinia H, Hasani E, Karami N, Pashaei N, Hatami S. The effect of low-dose remifentanil on the hemodynamic responses of endotracheal extubation. Acta Med Iran 2014;52:844-7.

17. Sadegi M, Firozian A, Ghafari MH, Esfehani F. Comparison in effect of intravenous alfentanil and lidocaine on airway-circulatory reflexes during extubation. Int J Pharmacol 2008;4:223-6.

18. Lee JY, Lim BG, Park HY, Kim NS. Sufentanil infusion before extubation suppresses coughing on emergence without delaying extubation time and reduces postoperative analgesic requirement without increasing nausea and vomiting after desflurane anesthesia. Korean J Anesthesiol 2012;62:512-7.

19. Zalunardo MP, Zollinger A, Spahn DR, Seifert B, Pasch T. Preoperative clonidine attenuates stress response during emergence from anesthesia. J Clin Anesth 2000;12:343-9.

20. Jain D, Khan RM, Maroof M. Effect of dexmedetomidine on stress response to extubation. Internet $\mathrm{J}$ Anesthesiol 2009;21:14.

21. Nagatani A, Shibata O, Haseba S, Fukuzaki M, Tomiyasu S, Tsuzaki $\mathrm{K}$, et al. The effect of nitroglycerin ointment on cardiovascular functions in hypertensive patients during emergence from anesthesia. Masui 1989;38:1312-6.

22. Nishina K, Mikawa K, Shiga M, Maekawa N, Obara H. Prostaglandin E1 attenuates the hypertensive response to tracheal extubation. Can J Anaesth 1996;43:678-83.

23. Ferasatkish R, Dabbagh A, Alavi M, Mollasadeghi G, Hydarpur E, Moghadam AA, et al. Effect of magnesium sulfate on extubation time and acute pain in coronary artery bypass surgery. Acta Anaesthesiol Scand 2008;52:1348-52.

24. Guler G, Akin A, Tosun Z, Eskitascoglu E, Mizrak A, Boyaci A. Single-dose dexmedetomidine attenuates airway and circulatory reflexes during extubation. Acta Anaesthesiol Scand 2005;49:1088-91.

25. Riessen R, Pech R, Tränkle P, Blumenstock G, Haap M. Comparison of the RAMSAY score and the Richmond Agitation Sedation Score for the measurement of sedation depth. Crit Care 2012;16:P326.

26. Asai T, Koga K, Vaughan RS. Respiratory complications associated with tracheal intubation and extubation. $\mathrm{Br} \mathrm{J}$ Anaesth 1998;80:767-75.

27. Mikawa K, Nishina K, Maekawa N, Obara H. Attenuation of cardiovascular responses to tracheal extubation: Verapamil versus diltiazem. Anesth Analg 1996;82:1205-10. 
28. Mikawa K, Nishina K, Takao Y, Shiga M, Maekawa N, Obara H. Attenuation of cardiovascular responses to tracheal extubation: Comparison of verapamil, lidocaine, and verapamil-lidocaine combination. Anesth Analg 1997;85:1005-10.

29. Sharma VB, Prabhakar H, Rath GP, Bithal PK. Comparison of dexmedetomidine and lignocaine on attenuation of airway and pressor responses during tracheal extubation. J Neuroanaesth Crit Care 2014;1:50-5.

30. Bindu B, Pasupuleti S, Gowd UP, Gorre V, Murthy RR, Laxmi MB. A double blind, randomized, controlled trial to study the effect of dexmedetomidine on hemodynamic and recovery responses during tracheal extubation. J Anaesthesiol Clin Pharmacol 2013;29:162-7.

31. Aksu R, Akin A, Biçer C, Esmaoglu A, Tosun Z, Boyaci A.
Comparison of the effects of dexmedetomidine versus fentanyl on airway reflexes and hemodynamic responses to tracheal extubation during rhinoplasty: A double-blind, randomized, controlled study. Curr Ther Res Clin Exp 2009;70:209-20.

32. Ali MA, Abdellatif AA. Prevention of sevoflurane related emergence agitation in children undergoing adenotonsillectomy: A comparison of dexmedetomidine and propofol. Saudi J Anaesth 2013;7:296-300.

How to cite this article: Mistry T, Purohit S, Arora G, Gill N, Sharma J. Attenuation of extubation responses: Comparison of prior treatment with verapamil and dexmedetomidine. J Neuroanaesthesiol Crit Care 2016;3:33-9.

Source of Support: Nil, Conflict of Interest: None declared. 